Graduate Institute of

International Studies I Geneva

Economics

HEI Working Paper No: 05/2008

\title{
Institution and Development Revisited: A Nonparametric Approach
}

\author{
Sudip Ranjan Basu \\ United Nations \\ Conference on Trade and Development, Geneva \\ Monica Das \\ Skidmore College, New York
}

\begin{abstract}
The paper uses nonparametric methodology to examine the role of institutions in understanding differential levels of development across countries. This technique estimates first order derivatives for every country allowing a deeper look into the impact of institutions on development. The preliminary cross-country findings show that (i) institutional quality positively and significantly increases development quality; and (ii) results remain 'robust' for different model specifications and choice of additional control variables. The analysis is carried out for a set of 102 countries over 1980 to 2004. Similar to parametric results established in the literature, the nonparametric analysis lends further support to the view that institutions matter in the context of economic policies and geographic factors.
\end{abstract}

(C) The Authors.

All rights reserved. No part of this paper may be reproduced without the permission of the authors. 


\title{
Institution and Development Revisited: A Nonparametric Approach
}

\author{
Sudip Ranjan Basu ${ }^{\dagger *}$ \\ Monica Das ${ }^{\dagger \dagger}$
}

This version, 11 March 2008

\begin{abstract}
The paper uses nonparametric methodology to examine the role of institutions in understanding differential levels of development across countries. This technique estimates first order derivatives for every country allowing a deeper look into the impact of institutions on development. The preliminary cross-country findings show that (i) institutional quality positively and significantly increases development quality; and (ii) results remain 'robust' for different model specifications and choice of additional control variables. The analysis is carried out for a set of 102 countries over 1980 to 2004. Similar to parametric results established in the literature, the nonparametric analysis lends further support to the view that institutions matter in the context of economic policies and geographic factors.
\end{abstract}

Keywords: Development, Institutions, Geography, Openness, Principal component, Nonparametric analysis

JEL Classification Numbers: C3, O10, O57, P51, R11

${ }^{\dagger}$ United Nations Conference on Trade and Development, Geneva.

${ }^{\dagger \dagger}$ Assistant Professor, Department of Economics, Skidmore College, New York.

*Part of the research was undertaken when author was a Ph.D. candidate at the Graduate Institute. The views expressed in this paper are those of the authors and do not necessarily reflect the views of the United Nations Secretariat or its members. Any errors in this paper are those of the authors

E-mail address: basu1@ @ei.unige.ch, sudip.ranjan.basu@ unctad.org, mdas@ skidmore.edu Fax: +41229070044 


\section{Introduction}

Do institutions cause differential levels of development across countries? Should the development agenda of an under-developed country be directed towards building institutions with standards similar to those of developed countries? ${ }^{1}$ What effects do institutions have on indicators of development? Answers to these questions are relevant for policy makers and planners worldwide.

The relevant literature states that geography, economic policy and institutions are the three most important determinants of a country's economic performance. The endowment hypothesis states that geography/ biogeographic or climatic conditions explain cross-country differences in economic performances (Diamond (1997), Gallup et. al. (1998), Masters and McMillan (2001) and Hibbs and Olsson $(2005,2004)) .{ }^{2}$ This body of literature suggests that, "Institutions Don't Rule" (Sachs (2003)). According to the policy hypothesis, efficient resource allocation by economic policy is responsible for faster economic growth (Sachs and Warner (1995), Edwards (1998), Frankel and Romar (1999), Dollar and Kraay (2001, 2003) and Wacziarg and Welch (2003)). ${ }^{3}$ The institutions hypothesis advocates that quality of institutions trumps both geography as well as policy in determining a country's level of development (Acemoglu, Johnson and Robinson (2001), Rodrik, Subramanian and Trebbi (2004), Easterly and Levine (2003) and Basu (2008)).

The purpose of our paper is to further investigate the institutions hypothesis. We use two innovative measures of development and institutional quality. Our paper explores the complexities of development and its interactions with institutions, geography and economic

\footnotetext{
${ }^{1}$ There is no established convention for the designation of "developed" and "developing" countries or areas in the United Nations system. In common practice, Japan in Asia, Canada and the United States in northern America, Australia and New Zealand in Oceania, and Europe are considered "developed" regions or areas. For details refer to the United Nations Statistics Division. Table A1 gives a complete list and classification of countries used in the paper.

${ }^{2}$ Gallup et. al control for macroeconomic policies, while Hibbs and Olsson (2005, 2004), control for institutions and economic policies. They find that only geography matters for economic performance.

${ }^{3}$ However, Stiglitz (1999), Rodriguez and Rodrik (2000) and Muqtada (2003) question the effectiveness of trade reform and macroeconomic polices on the economy, in the absence of institutional support.
} 
polices within the framework of nonparametric and semiparametric analysis. We focus on estimating the relationship between institutional and development quality in a data driven specification free manner.

The existing body of literature uses single indicators such as, GDP per capita as a proxy for development or the rule of law and property rights to measure institutional quality. For our analysis, we use two indices, the development quality index (DQI) and the institutional quality index (IQI), from the methodology proposed in Nagar and Basu (2002). These indices are capable of capturing a broader range of issues related to development and institutions. According to Acemoglu, Johnson and Robinson (2001), institutions positively influence GDP per capita, by securing property rights. ${ }^{4}$ Their estimates suggest that, geography does not cause variations in GDP per capita. Rodrik, Subramanian and Trebbi (2004) argue that institutions dominate geography and trade policies in influencing income levels around the world. Easterly and Levine (2003) show that economic policy has no effect on GDP per capita after controlling for institutions and geography effects a country's GDP indirectly via institutions. According to them, only institutions can explain cross-country variations in GDP per capita and institutional indicators would be a sufficient statistic to account for variations in economic performance. ${ }^{5}$ These studies argue that "Institutions Rule" over geography and economic policy. Basu (2008) strongly supports the importance of institutions in the context of specific economic policy mixes and geography. These highly quoted studies use parametric estimation techniques. The nature of the relationship between institutions and development is the heart of the issue. Therefore, we employ parametric and semiparametric estimators to investigate the relationship between various institutional and development indicators, in a cross-country context.

\footnotetext{
${ }^{4}$ In Acemoglu, Johnson and Robinson (2001), property rights are measured as average protection against expropriation risk.

${ }^{5}$ Bardhan (2005) argues that institutions could play an important role in determining economic performance, but question still remains "Institutions matter, but which ones?"
} 
We estimate a nonparametric and semiparametric model to capture the relationship between institutional quality and development quality for 102 countries from 1980 to 2004 . This flexible estimation strategy helps us examine the development-institution relationship in a data driven manner without superimposing any a priori functional form restriction. We also feel that the nonparametric estimation technique can be exploited to provide a deeper understanding of the relationship of interest. The nonparametric methodology gives us an estimate of the first order derivative of the development quality with respect to the institutional quality for every country.

We now plot a course for the rest of the paper. Section 2 presents the data and estimation technique used in the paper. Section 2.1 outlines the nonparametric methodology and section 2.2 discusses the semiparametric methodology. We discuss our main findings and results in Section 3. Section 4 concludes the paper.

\section{Data and Estimation}

Our paper is based on 102 countries, of which 76 are developing countries, 22 are OECD countries, and 29 are least developed and small-medium size countries, as defined by United Nations and WTO respectively (See Table A1 for a complete list). We look at data of indicators from several international sources, research institutions and think-tanks (See Table A2 for data sources of the indicators used in the paper). For our analysis, we compute two indices, the development quality index $(D Q I)$ and the institutional quality index $(I Q I)$, for 102 countries and for five time intervals: 1980-1984, 1985-1989, 1990-1994, 1995-1999, and 2000-2004. We take an average of the indices from each time interval to get the index values for a country over the entire period for our analysis.

The $D Q I$ is calculated from three aspects of development: economic, health and knowledge. Economic development indicators are, GDP per capita in PPP international 2000 
$\$$, telephone lines, television sets, radios, electric power consumption per capita, and energy use per capita; health development indicators are, life expectancy at birth, infant mortality rate, physicians, immunization of children, and $\mathrm{CO}_{2}$ emissions per capita; and knowledge development indicators are, adult literacy rate, primary school enrolment rate, secondary school enrolment rate and total number of years in schools. The $D Q I$ is a composite index, which covers 15 indicators of development. Likewise, the IQI is constructed to evaluate the quality of institutions. It is also calculated from three aspects of institutional quality: economic, social and political. Economic institutional quality is a combination of legal and property rights, bureaucratic quality, corruption, democratic accountability, government stability, law and order, independent judiciary, and regulation; social institutional quality is based on press freedom, civil liberties, physical integrity index, empowerment right index, freedom of association, women's political rights, women's economic right, and women's social right; and political institutional quality depends on executive constraint, index of democracy, political rights, polity score, lower legislative, upper legislative and independent sub-federal units. The IQI is based on 23 indicators of quality of institutions. ${ }^{6}$

\subsection{The Nonparametric Model}

To make our analysis robust, we use four indices of institutional quality: the political institutional quality index (PIQI), the social institutional quality index (SIQI), the economic institutional quality index $(E I Q I)$ and the total institutional quality index (IQI). The geography indicator $(G E O G)$ is the absolute distance of a country from the equator and the openness/ world integration indicator $(E P O L)$ is a trade/GDP ratio. Most studies concerned with the relationship between development and institutions, estimate a parametric equation of the form: $D Q I_{i}=\beta_{0}+\beta_{1} E P O L_{i}+\beta_{2} G E O G_{i}+\beta_{3} I Q I_{i}+v_{i}$.

\footnotetext{
${ }^{6}$ See A2 for definition and sources of DQI and IQI indicators.
} 
To capture the relationship between institutional quality and development quality, we replace a typical parametric model with the corresponding nonparametric model. This flexible estimation strategy helps us avoid any functional form misspecification bias and enables us to explore the shape of the underlying relationship without superimposing any $a$ priori functional form restriction. As a result, the development- institution relationship is examined in a data driven manner. We also feel that the nonparametric estimation technique can be exploited to provide a deeper understanding of the relationship of interest. The nonparametric methodology gives us an estimate of the slope coefficient for every country. Hence we can examine the relationship between $D Q I$ and the institutional quality indices: $I Q I, P Q I, S I Q I$ and EIQI, for each country. Equations (1) through (4) capture the nonparametric relationships between development and institutional quality indices. Here, $m_{1}(),. m_{2}(),. m_{3}($.$) and m_{4}($.$) are unknown smooth functions; and the classical error terms are,$ $v_{1 t}, v_{2 t}, v_{3 t}$ and $v_{4 t}$. We represent the set of equations in (1) through (4) with a general form in (5). $Y_{i}$ is the development quality index for the $i^{\text {th }}$ country, $\left\{X_{i}\right\}$ is the $1 \times 3$ matrix of independent variables, $v_{i}$ is a stochastic disturbance term and the sample size $n=102 .^{7}$

$$
\begin{aligned}
& D Q I_{i}=m_{l}\left(E P O L_{i}, G E O G_{i}, I Q I_{i}\right)+v_{l i} \\
& D Q I_{i}=m_{2}\left(E P O L_{i},{G E O G_{i}}, P I Q I_{i}\right)+v_{2 i} \\
& D Q I_{i}=m_{3}\left(E P O L_{i}, G E O G_{i}, S I Q I_{i}\right)+v_{3 i} \\
& D Q I_{i}=m_{4}\left(E P O L_{i}, G E O G_{i}, E I Q I_{i}\right)+v_{4 i} \\
& Y_{i}=m\left(X_{i}\right)+v_{i} \quad(i=1,2, \ldots n)
\end{aligned}
$$

We assume $m($.$) is a smooth function and the sample realizations \left\{Y_{i}, X_{i}\right\}$ are i.i.d. Then, we can estimate $m($.$) nonparametrically using kernel methods. Details of this$ estimation strategy are available in Silverman (1998), Pagan and Ullah (1999) and Li and

\footnotetext{
${ }^{7} X_{i}=\left[E P O L_{i} G E O G_{i} I Q I_{i}\right]$ in (1), $X_{i}=\left[E P O L_{i} G E O G_{i} P I Q I_{i}\right]$ in (2), $X_{i}=\left[E P O L_{i} G E O G_{i} S_{Q} I_{i}\right]$ in $(3)$ and $X_{i}=$ $\left[E P O L_{i} G_{E O G_{i}} E I Q I_{i}\right]$ in (4); $v_{i}=v_{1 i}$ in (1), $v_{i}=v_{2 i}$ in (2), $v_{i}=v_{3 i}$ in (3) and $v_{i}=v_{4 i}$ in (4).
} 
Raccine (2006). ${ }^{8}$ Taking a linear Taylor series expansion and considering terms up to the first order, we can re-write the local linear version of (5) as,

$$
Y_{i}=m(x)+\left(X_{i}-x\right)^{\prime} \beta(x)+\varepsilon_{i}
$$

In (10), $\varepsilon_{i}$ is the new error term that captures the remaining terms of the Taylor series expansion. ${ }^{9}$ In our notation, $m($.$) is the unknown conditional mean of Y_{i}, \beta($.$) is a vector of the$ partial derivative of $Y_{i}$ with respect to $\left\{X_{i}\right\},\left\{X_{i}^{\prime}\right\}$ is a $(1 \diamond 3)$ matrix of explanatory variables and $x^{\prime}$ is a $(1 \diamond 3)$ matrix of actual data. Re-arranging terms in (6), we get, $Y_{i}=Z_{i} \delta(x)+\varepsilon_{i}$,

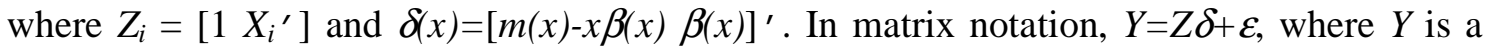
$(n \times 1)$ matrix of dependent variables, $Z$ is a $(n \times 4)$ matrix of ones and independent variables, $\delta$ is a (4×1) matrix of parameters and $\varepsilon$ is a $(n \times 1)$ matrix of stochastic errors. We minimize the weighted sum of squares of residuals, $S=\left(K^{1 / 2} Y-K^{1 / 2} Z \delta\right)^{\prime}\left(K^{1 / 2} Y-K^{1 / 2} Z \delta\right)$, to obtain the local linear least squares estimates (LLLS) $\delta_{L L L S}=\left(Z^{\prime} K Z\right)^{-1}\left(Z^{\prime} K Y\right)$, where $V\left(\delta_{L L L S}\right)=\sigma^{2}\left(Z^{\prime} K Z\right)^{-}$ ${ }^{1}\left(Z^{\prime} K K^{\prime} Z\right)\left(Z^{\prime} K Z\right)^{-1}$. The $n \times n$ matrix of weights $K(x)=\operatorname{Diag}\left(K\left(\left(X_{i}-x\right) / h\right)\right)$. It is well known in the literature that the choice of kernels does not influence significantly the efficiency of LLLS estimates (Silverman, 1998, Table 3.1, pg 43). The choice of window width is however crucial. Small values of $h$ cause over smoothing and high values lead to under smoothing of the estimates. The optimum $h$ is the one that minimizes the integrated mean squared error of $m(x){ }^{10}$ To make the LLLS estimate feasible, we estimate $\hat{\sigma}^{2}=1 /(n-k-1) \sum e_{i}{ }^{2}$, where $e_{i}$ is the least squares residual from (5).

We obtain the local linear generalized least squares (LLGLS) estimates by minimizing the weighted sum of squares of residuals $\mathrm{S}^{\prime}=(Y-Z \delta)^{\prime} K^{1 / 2} \Omega^{-1} K^{1 / 2}(Y-Z \delta)$ with

\footnotetext{
${ }^{8}$ For a simple exposition refer to Das (2008).

${ }^{9}$ We assume that $E\left(\varepsilon_{i}\right)=0$ and $V\left(\varepsilon_{i}\right)=\sigma^{2}$.

10 We choose the multivariate Gaussian kernel density function $K(x)=\stackrel{3}{\Pi_{q}=1}(1 / \sqrt{2} \pi) \exp \left(\left(x_{i q}-x_{q}\right) / 2 h_{q}\right)^{2}, \mathrm{~h}_{\mathrm{q}}=$ $1.06 \mathrm{n}^{-1 / 5} \mathrm{~s}_{\mathrm{xq}}$ and $\mathrm{s}_{\mathrm{xq}}$ is the standard error of the $\mathrm{q}^{\text {th }}$ independent variable.
} 
respect to $\delta(x)$. Essentially, we apply the least squares estimation on the transformed observations $\Omega^{-1 / 2} K^{1 / 2} Y$ and $\Omega^{-1 / 2} K^{1 / 2} X$ and obtain $\delta_{L L G L S}=\left(Z^{\prime} K^{1 / 2} \Omega^{-1} K^{1 / 2} Z\right)^{-1}\left(Z^{\prime} K^{1 / 2} \Omega^{-1} K^{1 / 2} Y\right)$ with $V\left(\delta_{L L G L S}\right)=\left(Z^{\prime} \theta Z\right)^{-1} Z^{\prime} \theta \Omega^{-1} \theta^{\prime} Z\left(Z^{\prime} \theta Z\right)^{-1}$, where $\theta=K^{1 / 2} \Omega^{-1} K^{1 / 2}$. Following the suggestions of Hinkley (1977), to make the LLGLS estimates feasible, we estimate $\hat{\Omega}=(n /(n$ $k)) \varsigma$, where a typical element of $\varsigma=\operatorname{diag}\left(e_{1}^{2}, e_{2}^{2} \ldots e_{n}^{2}\right) .{ }^{11}$ Both LLLS and LLGLS estimates are consistent. Their asymptotic properties are established in Pagan and Ullah (1999) and Li and Raccine (2006).

\subsection{The Semiparametric Model}

To check for robustness of our nonparametric estimates, we introduce several geographical variables into our original model. These geographical variables are, the geographical dummy for Africa (reg_africa), Asia (reg_asia) and Latin America (reg_lac). We consider the semiparametric model of Yatchew (2003). Equations (7) through (10) are partially linear models where the regression equation has both parametric as well as unspecified components. Here, $m_{5}(),. m_{6}(),. m_{7}($.$) and m_{8}($.$) are unknown smooth functions$ and the classical error terms are, $v_{5 t}, v_{6 t}, v_{7 t}$ and $v_{8 t}$. We represent the set of equations in (7) to (10) with a general form in (11). $Y_{i}$ is the development quality index for the $i^{\text {th }}$ country, $Z_{i}=$ $\left[G E O G_{i} r e g \_a f r i c a_{i} r e g \_a s i a_{i} r e g \_l a c_{i}\right]$ is a $(1 \times 4)$ matrix of geography dummies, $X_{i}$ is a $(1 \times 2)$ matrix of independent variables and $v_{i}$ is a stochastic disturbance term. ${ }^{12}$ Equation (12) is the matrix form representation of equation (11). $Y=\left[Y_{i}\right]$ is a $(\mathrm{n} \times 1)$ vector of dependent variables, $Z=\left[Z_{i}\right]$ is a $(\mathrm{n} \times 4)$ vector of geography dummies, which have a parametric relationship with $Y$

\footnotetext{
${ }^{11}$ It is well known that White corrected $t$ values tend to be too large. Hence we use Hinkley's estimates for the variance covariance matrix. We also follow Horn and Duncan's (1975) suggestion of using $S=\operatorname{diag}\left({s_{1}}^{2}, . . s_{n}{ }^{2}\right)$, where $s_{i}^{2}=e_{i}^{2} /\left(1-m_{i i}\right)$ and $m_{i i}=$ diagonal element of $X(X X)^{-1} X^{\prime}$. Results from Horn and Duncan's methodology are very similar to the results from Henkley (1977). So only Henley estimates are used to make the LLGLS estimates feasible.

${ }^{12} X_{i}=\left[E P O L_{i} I Q I_{i}\right]$ in (7), $X_{i}=\left[E P O L_{i} P I Q I_{i}\right]$ in (8), $X_{i}=\left[E P O L_{i} S I Q I_{i}\right]$ in (9) and $X_{i}=\left[E P O L_{i} E I Q I_{i}\right]$ in (10); $v_{i}=v_{5 i}$ in (7), $v_{i}=v_{6 i}$ in (8), $v_{i}=v_{7 i}$ in (9) and $v_{i}=v_{8 i}$ in (10).
} 
and $X=\left[X_{i}\right]$ is a $(\mathrm{n} \times 2)$ matrix of independent variables, which have a nonparametric relationship with $Y$. We assume that $E(\varepsilon \mid Z, X)=0$ and $V(\varepsilon \mid Z, X)=\sigma_{\varepsilon}^{2}$.

$$
\begin{aligned}
D Q I_{i}= & m_{5}\left(E P O L_{i}, I Q I_{i}\right)+\beta_{0} G E O G_{i}+\beta_{1} r e g_{-} \text {asia }+\beta_{2} r e g_{-} \text {africa }+\beta_{3} r e g_{-} l a c+v_{5 i} \\
D Q I_{i}= & m_{6}\left(E P O L_{i}, P I Q I_{i}\right)+\beta_{0} G E O G_{i}+\beta_{1} r e g_{-} \text {asia }+\beta_{2} r e g_{-} \text {africa }+\beta_{3} r e g_{-} l a c+v_{6 i} \\
D Q I_{i}= & m_{7}\left(E P O L_{i}, S I Q I_{i}\right)+\beta_{0} G E O G_{i}+\beta_{1} r e g_{-} \text {asia }+\beta_{2} r e g_{-} \text {africa }+\beta_{3} r e g_{-} l a c+v_{7 i} \\
D Q I_{i}= & m_{8}\left(E P O L_{i}, E I Q I_{i}\right)+\beta_{0} G E O G_{i}+\beta_{1} r e g_{-} \text {asia }+\beta_{2} r e g \_a f r i c a+\beta_{3} r e g \_l a c+v_{8 i}(10) \\
& Y_{i}=m\left(X_{i}\right)+Z_{i}{ }^{\prime} \beta+v_{i} \\
& Y=m(X)+Z \beta+\varepsilon
\end{aligned}
$$

We suppose that the conditional mean of $Z, E(Z \mid X)$ is a smooth bounded function of $X$, say $g(X)$ and $V(Z \mid X)=\sigma_{u}^{2}$. Then, we may write $Z=g(X)+u$. Differencing yields, $\left(Y_{i}-Y_{i-1}\right)$ $=\left(Z_{i}-Z_{i-1}\right) \beta+\left(f\left(X_{i}\right)-f\left(X_{i-1}\right)\right)+\varepsilon_{i-} \varepsilon_{i-1}$. Applying OLS to the differenced data, we get $b_{D I F F}=\Sigma\left(Y_{i}-\right.$ $\left.Y_{i-1}\right)\left(Z_{i}-Z_{i-1}\right) / \Sigma\left(Z_{i}-Z_{i-1}\right)^{2}$. The semiparametric estimates are obtained by applying local linear least squares to the transformed model: $Y-Z b_{D I F F}=m(X)+\varepsilon$. Yatchew (2003) works out the consistency properties of the semiparametric estimates.

\section{3: Results}

For the parametric results of a similar model, we urge the reader to refer to Basu (2008). In this paper, we focus on the nonparametric model and results. We estimate the nonparametric regression functions in (1) through (4) with local linear least squares methodology outlined in section 2.1. A challenge with using nonparametric technology is that we obtain 102 estimates of first order derivatives for each independent variable. To keep the analysis manageable, we focus on the main relationship of interest, the developmentinstitution relationship. The nonparametric estimates of first order derivatives are represented by $\delta=\left\{\begin{array}{llll}\delta_{1} & \delta_{2} & \delta_{3} & \delta_{4}\end{array}\right\}$, where $\delta_{1}=\partial D Q I / \partial I Q I, \quad \delta_{2}=\partial D Q I / \partial P I Q I, \quad \delta_{3}=\partial D Q I / \partial S I Q I$ and $\delta_{4}=$ 
$\partial D Q I / \partial E I Q I$. The advantage of using nonparametric technology in this context is that we are able to estimate the first order derivative $\delta$, for every country in the sample. Thus we are able to gain a deeper understanding of the relationship between development and institutions, for the countries included in our dataset. Out of all the LLLS estimates of $\delta_{l}, 28 \%$ are significant at $1 \%$ level, $25 \%$ are significant at $5 \%$ level and $10 \%$ are significant at $10 \%$ level of significance. None of the LLLS estimates of $\delta_{2}, \delta_{3}$ and $\delta_{4}$ are significant at $10 \%$.

The LLLS estimates are insignificant for most countries even at $10 \%$ levels. This is not surprising since the analysis till this stage disregards the information contained in the variance covariance matrix $\Omega$. Classical techniques assume that the stochastic disturbances have constant variance. However, as long as $\Omega \neq \sigma^{2} I$, the LLLS estimates are not efficient. To deal with the problem, we compute the LLGLS estimates. We represent the LLGLS estimates of the first order derivatives by $\gamma=\left\{\begin{array}{llll}\gamma_{1} & \gamma_{2} & \gamma_{3} & \gamma_{4}\end{array}\right\}$, where $\gamma_{1}=\partial D Q I / \partial I Q I, \gamma_{2}=\partial D Q I / \partial P I Q I, \gamma_{3}=$ $\partial D Q I / \partial S I Q I$ and $\gamma_{4}=\partial D Q I / \partial E I Q I$. All LLGLS estimates of $\gamma_{1}$ are significant at the $1 \%$ level. Out of the remaining LLGLS estimates, $85 \%$ of estimates of $\gamma_{2}, 27 \%$ of estimates of $\gamma_{3}$ and $12 \%$ of $\gamma_{4}$ are significant at the $1 \%$ level. Some nonparametric estimates are negative. We present all LLLS estimates in table 1 and all LLGLS estimates in table2. We observe that about $80 \%$ of all LLLS and LLGLS estimates indicate a positive relationship between development and institutional indicators.

As explained by Robinson (1988), a reasonable parametric model affords precise inferences, a badly misspecified one, possibly misleading inferences, while a nonparametric model is associated with greater robustness and lesser precision. Therefore we employ the intermediate strategy of conducting a semiparametric regression. We estimate the semiparametric models in (7) to (10). We represent the semiparametric estimates of the first order derivatives by $\phi=\left\{\begin{array}{llll}\phi_{1} & \phi_{2} & \phi_{3} & \phi_{4}\end{array}\right\}$, where $\phi_{1}=\partial D Q I / \partial I Q I, \quad \phi_{2}=\partial D Q I / \partial P I Q I, \quad \phi_{3}=$ $\partial D Q I / \partial S I Q I$ and $\phi_{4}=\partial D Q I / \partial E I Q I$. Out of the semiparametric estimates, $94 \%$ of estimates of 
$\phi_{1}, 30 \%$ of estimates of $\phi_{2}, 87 \%$ of estimates of $\phi_{3}$ and $32 \%$ of estimates of $\phi_{4}$ are significant at the $1 \%$ level. $84 \%$ of all semiparametric estimates indicate a positive relationship between development and institutional indicators. Details are available in table 3. Figure1 compares the LLLS estimates of $\delta=\left\{\begin{array}{llll}\delta_{1} & \delta_{2} & \delta_{3} & \delta_{4}\end{array}\right\}$, figure 2 compares the LLGLS estimates of $\gamma= \begin{cases}\gamma_{1} & \gamma_{2}\end{cases}$ $\left.\gamma_{3} \gamma_{4}\right\}$ and figure 3 compares the semiparametric estimates of $\phi=\left\{\phi_{1} \phi_{2} \phi_{3} \phi_{4}\right\}$.

\section{4: Conclusions}

The results of the nonparametric model of our paper support the notion that in general "Institutions Rule". The level of institutional quality is an important determinant of development quality at the cross-country level for the time period of 25 years. It is possible that countries with better institutional quality are in a better position to reap benefits from trade integration and geography. On the other hand, countries with weak institutional quality find it difficult to enhance their overall development level. Overall, our preliminary results indicate that in addition to significance of institutions, the role of economic policies and geography are also key in determining the level of development. Hence, the level of institutions, economic policies and geography are the three key determinants of the differential levels of development across countries. Their relative significance in explaining development quality depends on the exact stage of development of the country.

In general, we believe that the novelty of our paper is the use of non-parametric technique to understand the importance of institutions in development of a country. Our results strongly support the findings of Basu (2008) in the context of parametric framework. Future research will investigate the development-institution relationship further by estimating a fixed/ random effects nonparametric model. The model can be enhanced by adding more covariates, which can capture the channels followed by countries to climb up in the ladder of development. 


\section{Reference}

Acemoglu, D., S. Johnson, and J. A. Robinson (2001). "The Colonial Origins of Comparative Development: An Empirical Investigation," American Economic Review 91 (5) 1369 - 1401.

Bardhan, P. (2005). "Institutions matter, but which ones?" Economics of Transition 13.

Basu, S.R. (2008). "A new way to link development to institutions, policies and geography", Policy issues in international trade and commodities, UNCTAD/ITCD/TAB/38, United Nations, New York and Geneva (forthcoming).

HEI Working Paper Number: 04-2008, International Economics Department, Graduate Institute of International Studies, Geneva. March 2008.

Cingranelli-Richards (CIRI). "Human Rights Dataset". http://ciri.binghamton.edu/

Das, M. (2008) "Nonparametric Estimation" International Encyclopedia of the Social Sciences Ed. William A. Darity, Jr. $2^{\text {nd }}$ ed. Detroit: Macmillan Reference USA Vol 5524 527.

Diamond, J. (1997). Guns, Germs, and Steel, New York: W.W. Norton \& Co.

Dollar, D. and A. Kraay (2001). “Trade, Growth, and Poverty,” World Bank, Policy Research Working Paper No. 2199.

Dollar, D. and A. Kraay (2003). "Institutions, Trade, and Growth: Revisiting the Evidence," Policy Research Working Paper Series 3004, The World Bank

Easterly, W. and R. Levine (2003). "Tropics, Germs, and Crops: How Endowments Influence Economic Development," Journal of Monetary Economic 50 (1) 3 - 39.

Edwards, S. (1998). 'Openness, Productivity and Growth: What do we really know?' Economic Journal, 108, 383-398

Frankel, J.A. and D. Romer, (1999). "Does Trade Cause Growth?," American Economic Review 89.

Gallup, J.L., J.D. Sachs and A.D. Mellinger (1998). "Geography and Economic Development," Harvard Institute of Economic Research Working Papers 1856, Harvard Institute of Economic Research.

Hibbs, D.A. and O. Olsson (2004). "Geography, biogeography, and why some countries are rich and others are poor", PNAS, 101.

Hibbs, D. A., and O. Olsson (2005). "Biogeography and long-run economic development" European Economic Review 49.

Hinkley, D.V., 1977, “Jackknifing in unbalanced situations”, Technometrics 19, 285-292.

Horn, SD., R.A. Horn and D.B. Duncan, 1975, "Estimating heteroskedastic variances in linear models", Journal of the American Statistical Association 70, 380-385. 
Li, Q. and J. Racine (2007) Nonparametric Econometrics, Princeton University Press, New Jersey.

Masters, W.A. and M.S.McMillan (2001). "Climate and Scale in Economic Growth," Journal of Economic Growth 6.

Muqtada, M (2003). "Macroeconomic Stability, Growth and Employment: Issues and Considerations Beyond the Washington Consensus," EMP Working Paper \# 48, International Labour Organization, Geneva.

Nagar, A.L. and S. R. Basu. (2002). "Weighting Socio-Economic Indicators of Human Development: A Latent Variable Approach," in Ullah, A. et al (eds.) Handbook of Applied Econometrics and Statistical Inference, Marcel Dekker, New York, USA.

Pagan, A. and A. Ullah (1999) Nonparametric Econometrics, New York: Cambridge University Press.

Polity IV Project (2003). "Political Regime Characteristics and Transitions, 1800-2003," by M.G. Marshall, K. Jaggers, and T.R. Gurr. http://www.cidcm.umd.edu/inscr/polity/

PRIO (International Peace Research Institute). "Vanhanen's index of democracy," http://www.prio.no/cwp/vanhanen/

PRS Group (2006). International Country Risk Guide (ICRG). http://www.prsgroup.com/

Robinson, P. M., 1988, "Root N Consistent Semiparametric Regression,” Econometrica, 56 (4) $931-954$.

Rodrik, D., A. Subramanian and F. Trebbi, (2004). "Institutions Rule: The Primacy of Institutions over Geography and Integration in Economic Development," Journal of Economic Growth, 9 (2) 131 - 165.

Sachs, J.D. (2003). "Institutions Don't Rule: Direct Effects of Geography on Per Capita Income," NBER Working Papers 9490, National Bureau of Economic Research.

Sachs, J.D. and A.Warner (1995). "Economic reform and the Process of Global Integration,"Brookings paper on Economic Activity, 1, 1-118.

Silverman, B. W., 1998 "Density Estimation for Statistics and Data Analysis" Monographs on Statistics and Applied Probability, 26.

Stiglitz, J. (1999). "Whither Reform? Ten Years of the Transition," ABCDE, World Bank, Washington, D.C. April 28-30.

Wacziarg, R and K.H. Welch (2003). "Trade Liberalization and Growth: New Evidence". NBER Working Paper No. 10152.

Yatchew, A., 2003, Semiparametric Regression for the Applied Econometrician, Cambridge University Press, New York. 
Table 1: Local Linear Least Squares Derivatives

\begin{tabular}{|c|c|c|c|c|c|c|c|c|c|}
\hline CCODE & $\delta_{1}$ & $\delta_{2}$ & $\delta_{3}$ & $\delta_{4}$ & CCODE & $\delta_{1}$ & $\delta_{2}$ & $\delta_{3}$ & $\delta_{4}$ \\
\hline AGO & $1.078 *$ & 0.202 & 0.058 & 0.149 & KEN & 1.659 & 4.168 & 0.194 & 0.258 \\
\hline$A \mathbf{L B}$ & $1.059 * *$ & 0.285 & 0.194 & 0.328 & KOR & $0.918^{*}$ & 4.055 & 0.128 & 0.094 \\
\hline ARE & 0.901 & 0.25 & -1.819 & -1.71 & KWT & 0.931 & 0.53 & 1.221 & -0.529 \\
\hline ARG & $1.67 *$ & 3.322 & 0.235 & -0.082 & LBR & $1.066^{*}$ & -0.188 & -0.168 & -0.047 \\
\hline AUS & $1.497 *$ & 4.134 & 0.358 & -0.025 & LKA & $1.713 * *$ & 4.341 & 0.083 & 0.044 \\
\hline AUT & $0.769 *$ & 4.421 & 1.082 & 0.231 & LUX & 0.948 & 0.107 & 0.355 & 0.161 \\
\hline BEL & $0.852 *$ & 4.493 & 1.527 & 0.049 & MAR & 4.015 & 1.948 & -0.194 & -0.096 \\
\hline BGD & 1.698 & 3.633 & 0.376 & -0.062 & MDG & 3.994 & 2.455 & 0.013 & -0.027 \\
\hline BGR & 0.956 & 0.536 & 0.315 & -2.342 & MEX & $2.139 *$ & 5.202 & -0.285 & -0.34 \\
\hline BHR & $0.996 * *$ & 0.068 & -0.194 & -0.225 & MLI & 4.142 & 2.245 & 0.068 & 0.038 \\
\hline BOL & $1.713 * *$ & 4.219 & -0.188 & -0.191 & MOZ & 1.724 & 3.912 & -0.037 & -0.116 \\
\hline BRA & $1.672 * *$ & 3.51 & 0.176 & 0.253 & MWI & $1.743 * *$ & 4.321 & -0.176 & -0.18 \\
\hline BWA & $1.078^{*}$ & 0.33 & 0.18 & 0.269 & MYS & $1.628 * *$ & 4.452 & 0.163 & 0.118 \\
\hline CAN & $1.44 *$ & 4.17 & 0.124 & 0.083 & NER & $1.079 * *$ & 0.173 & -0.004 & -0.354 \\
\hline CHE & 0.967 & 0.268 & 0.15 & -0.001 & NGA & 3.14 & 5.373 & -0.184 & -0.169 \\
\hline CHL & 2.237 & 4.318 & 0.055 & 0.037 & NIC & $1.726 * *$ & 4.275 & 0.071 & 0.064 \\
\hline CHN & $1.043 * *$ & 0.391 & -0.222 & -0.474 & NLD & $1.005 *$ & 0.272 & 0.09 & -0.004 \\
\hline CIV & 3.66 & 3.072 & -0.191 & -0.127 & NOR & 0.428 & 4.406 & 0.159 & 0.1 \\
\hline CMR & 3.346 & 5.083 & -0.08 & -0.066 & NZL & $1.497 *$ & 4.211 & 0.093 & 0.148 \\
\hline COL & $1.706^{* *}$ & 4.112 & -0.185 & -0.156 & OMN & $1.014 * *$ & 0.225 & 0.161 & 0.152 \\
\hline CRI & $1.569 *$ & 4.365 & 0.097 & 0.071 & PAK & 3.38 & 4.133 & -0.031 & -0.029 \\
\hline DNK & 0.987 & 0.245 & -0.128 & -0.047 & PAN & $1.669 * *$ & 4.428 & 0.151 & 0.242 \\
\hline DOM & $1.652 *$ & 4.311 & 0.193 & 0.268 & PER & 2.95 & 4.871 & -0.043 & -0.024 \\
\hline DZA & $1.624 *$ & 4.083 & -0.097 & -0.211 & PHL & 3.66 & 2.251 & 0.021 & 0.005 \\
\hline ECU & $1.685^{*}$ & 4.298 & -0.158 & -0.217 & PNG & $1.079 *$ & 0.405 & 0.037 & 0.354 \\
\hline EGY & $1.739 *$ & 4.141 & 0.072 & 0.106 & POL & 0.949 & -0.494 & 1.666 & 0.011 \\
\hline ESP & $1.035^{* *}$ & 0.341 & -0.048 & -0.01 & PRT & $1.128^{*}$ & 4.379 & 1.187 & -0.178 \\
\hline ETH & 1.688 & 3.523 & 0.076 & 0.113 & PRY & $1.728 *$ & 4.238 & 0.142 & 0.231 \\
\hline FIN & 0.321 & 4.372 & 0.114 & 0.26 & ROM & 1.014 & 0.378 & 0.277 & 0.029 \\
\hline FRA & 2.883 & 3.94 & 0.005 & -0.03 & SAU & 0.982 & 0.357 & 0.037 & 0.104 \\
\hline GAB & $1.058 * *$ & 0.325 & 0.18 & 0.113 & SDN & $1.077 *$ & 0.015 & 0.147 & -0.326 \\
\hline GBR & $1.862 *$ & 5.015 & -0.144 & -0.252 & SEN & 4.093 & 2.156 & 0.011 & -0.027 \\
\hline GHA & 3.828 & 2.814 & 0.046 & 0.025 & SGP & 0.761 & 3.262 & 0.01 & -0.019 \\
\hline GIN & $1.077 *$ & 0.343 & 0.062 & 0.133 & SLV & 3.827 & 2.27 & 0.077 & -0.015 \\
\hline GNB & $1.067 *$ & 0.4 & 0.024 & 0.103 & SWE & 0.318 & 4.395 & 0.113 & 0.27 \\
\hline GRC & $1.041 * *$ & 0.339 & -0.146 & -0.945 & SYR & $1.078 *$ & 0.457 & 0.178 & 0.356 \\
\hline GTM & $1.729 *$ & 4.122 & -0.185 & -0.199 & TGO & $1.075^{* *}$ & 0.436 & 0.02 & 0.163 \\
\hline GUY & 1.667 & 4.178 & 0.176 & 0.281 & THA & $1.551 *$ & 4.389 & -0.018 & -0.182 \\
\hline HND & 3.869 & 2.087 & 0.015 & -0.002 & TTO & $1.609 *$ & 4.626 & -0.173 & -0.161 \\
\hline HTI & 4.087 & 2.449 & 0.019 & -0.029 & TUN & $1.722 *$ & 4.271 & 0.159 & 0.245 \\
\hline HUN & $1.051 * *$ & 0.102 & 0.195 & -0.095 & TUR & $1.067 * *$ & 0.311 & 0.075 & 0.072 \\
\hline IDN & $1.748^{*}$ & 4.239 & -0.205 & -0.255 & TZA & $1.697 * *$ & 4.46 & -0.213 & -0.282 \\
\hline IND & $1.676^{* *}$ & 3.43 & 0.088 & 0.14 & UGA & 4.055 & 2.662 & -0.037 & -0.019 \\
\hline IRL & $0.811^{*}$ & 4.483 & 0.034 & 0.228 & URY & $1.672 * *$ & 4.116 & 0.077 & 0.074 \\
\hline IRN & $1.066^{*}$ & 0.257 & 0.297 & -0.01 & USA & $1.04 *$ & 4.215 & -0.103 & -0.129 \\
\hline ISL & 0.394 & 4.013 & 0.116 & 0.086 & VEN & $1.668 *$ & 4.249 & 0.117 & 0.087 \\
\hline ISR & $1.008 *$ & 0.22 & 0.147 & 0.219 & VNM & $1.07 *$ & -0.044 & 0.906 & -0.747 \\
\hline ITA & $0.851 *$ & 4.282 & 0.448 & -0.166 & ZAF & 3.378 & 3.275 & 0.046 & 0.025 \\
\hline JAM & $1.645^{* *}$ & 4.372 & 0.176 & 0.265 & ZAR & $1.078 *$ & 0.431 & 0 & 0.128 \\
\hline JOR & $1.067 * *$ & 0.262 & 0.203 & 0.071 & ZMB & $1.725 * *$ & 4.338 & 0.203 & 0.157 \\
\hline JPN & $1.003 *$ & 0.265 & 0.134 & 0 & ZWE & 1.662 & 3.999 & -0.699 & -0.705 \\
\hline
\end{tabular}

Notes: *Significant at 1 percent, **Significant at 5 percent and *** Significant at 10 percent. 
Table 2: Local Linear Generalized Least Squares Derivatives

\begin{tabular}{|c|c|c|c|c|c|c|c|c|c|}
\hline ccode & $\gamma_{1}$ & $\gamma_{2}$ & $\gamma_{3}$ & $\gamma_{4}$ & ccode & $\gamma_{1}$ & $\gamma_{2}$ & $\gamma_{3}$ & $\gamma_{4}$ \\
\hline AGO & $1.07 *$ & $0.32 *$ & 0 & $0.14^{*}$ & KEN & $1.83 *$ & $4.05^{*}$ & $0.27 *$ & $0.16^{*}$ \\
\hline ALB & $1.08 *$ & $0.29 *$ & $0.19 *$ & $0.27 *$ & KOR & $0.8^{*}$ & $3.87 *$ & $0.1 *$ & -0.02 \\
\hline ARE & $0.86^{*}$ & $0.31 *$ & -1.89 & -1.7 & KWT & $0.92 *$ & $0.49 *$ & $1.25 *$ & -0.35 \\
\hline ARG & $1.84 *$ & $3.31 *$ & 0.06 & 0.03 & LBR & $1.07 *$ & $-0.31 *$ & -0.17 & 0.02 \\
\hline AUS & $1.74 *$ & $4.05^{*}$ & $0.41 *$ & -0.05 & LKA & $2 *$ & $4.46^{*}$ & $0.34 * *$ & -0.03 \\
\hline AUT & $0.75^{*}$ & $4.61 *$ & 0.78 & 0.41 & LUX & $0.96^{*}$ & $0.34 * *$ & $0.43^{*}$ & 0.09 \\
\hline BEL & $0.8^{*}$ & $4.59 *$ & $1.31 *$ & 0.27 & MAR & $4.39 *$ & 2.68 & -0.28 & -0.14 \\
\hline BGD & $1.96^{*}$ & $3.54 *$ & $0.33 *$ & 0.07 & MDG & $4.21 *$ & $3.56^{* *}$ & 0.02 & 0.01 \\
\hline BGR & $0.93 *$ & $0.47 *$ & $0.23 * * *$ & -2.77 & MEX & $2.51 *$ & $5.24 *$ & -0.3 & -0.32 \\
\hline BHR & $1.01 *$ & $0.06^{*}$ & -0.22 & -0.11 & MLI & $4.32 *$ & $3.36 * * *$ & $0.06^{*}$ & 0.02 \\
\hline BOL & $2 *$ & $4.18^{*}$ & -0.2 & -0.11 & MOZ & $1.87 *$ & $3.74 *$ & -0.06 & -0.12 \\
\hline BRA & $1.88 *$ & $3.46^{*}$ & $0.26^{*}$ & $0.15 * *$ & MWI & $2.14 *$ & $4.4 *$ & -0.17 & -0.12 \\
\hline BWA & $1.07 *$ & $0.4^{*}$ & $0.26^{*}$ & $0.12 * *$ & MYS & $1.75^{*}$ & $4.51 *$ & 0.09 & 0.09 \\
\hline CAN & $1.72 *$ & $4.09 *$ & $0.39 *$ & 0 & NER & $1.07 *$ & $0.19 *$ & 0.11 & -0.35 \\
\hline CHE & $0.96^{*}$ & $0.31 *$ & $0.25^{* *}$ & 0 & NGA & $3.26^{*}$ & $5.43 *$ & -0.28 & -0.2 \\
\hline CHL & $1.98 *$ & $4.65^{*}$ & $0.07 *$ & $0.04 *$ & NIC & $2.05^{*}$ & $4.3^{*}$ & $0.3 * *$ & -0.05 \\
\hline CHN & $1.07 *$ & $0.34 *$ & -0.26 & -0.36 & NLD & $1.01 *$ & $0.31 *$ & $0.32 * *$ & 0 \\
\hline CIV & $4.2^{*}$ & $4.2 *$ & -0.28 & -0.16 & NOR & $0.43 *$ & $4.57 *$ & $0.11 * *$ & 0.08 \\
\hline CMR & $3.43^{*}$ & $5.02 *$ & -0.11 & -0.08 & NZL & $1.79 *$ & $4.16^{*}$ & $0.28 * *$ & 0 \\
\hline COL & $1.98 *$ & $4.05 *$ & -0.18 & -0.13 & OMN & $1.02 *$ & $0.3^{*}$ & $0.11 * *$ & $0.11 *$ \\
\hline CRI & $1.73 *$ & $4.52 *$ & $0.36 * *$ & -0.02 & PAK & $4.08^{*}$ & $4.26^{*}$ & -0.06 & -0.04 \\
\hline DNK & $1^{*}$ & $0.32 *$ & -0.07 & 0 & PAN & $1.86^{*}$ & $4.47 *$ & $0.24 *$ & $0.14 * * *$ \\
\hline DOM & $1.78^{*}$ & $4.4^{*}$ & $0.26^{*}$ & $0.24 *$ & PER & $3.64 *$ & $4.8^{*}$ & -0.03 & 0 \\
\hline DZA & $1.85^{*}$ & $3.87 *$ & -0.04 & -0.09 & PHL & $4.1^{*}$ & $3.41 * * *$ & 0.03 & 0.01 \\
\hline ECU & $1.88^{*}$ & $4.34 *$ & -0.13 & -0.13 & PNG & $1.08 *$ & $0.34 *$ & -0.01 & $0.41 *$ \\
\hline EGY & $2.05^{*}$ & $4.02 *$ & $0.25 * * *$ & -0.05 & POL & $0.93 *$ & $-0.78 *$ & $1.8^{*}$ & -0.07 \\
\hline ESP & $1.04 *$ & $0.32 *$ & -0.1 & -0.02 & PRT & $1.14 *$ & $4.51 *$ & $1.39 *$ & -0.11 \\
\hline ETH & $1.7 *$ & $3.4^{*}$ & $0.28 * *$ & -0.04 & PRY & $2.03 *$ & $4.21 *$ & $0.24 * *$ & $0.13 * * *$ \\
\hline FIN & $0.28 *$ & $4.46^{*}$ & $0.12 *$ & $0.19 *$ & ROM & $1.01 *$ & $0.33^{*}$ & $0.3^{*}$ & $0.1^{*}$ \\
\hline FRA & $3.67 *$ & $4.24 *$ & 0.02 & -0.03 & SAU & $1 *$ & $0.31 *$ & -0.01 & 0.07 \\
\hline GAB & $1.06^{*}$ & $0.31 *$ & 0.1 & 0.06 & SDN & $1.08 *$ & 0.15 & 0.05 & -0.25 \\
\hline GBR & $2.13 *$ & $5.06 *$ & -0.23 & -0.28 & SEN & $4.37 *$ & $3.27 * * *$ & 0.02 & 0.01 \\
\hline GHA & $4.07 *$ & $3.67 *$ & $0.05^{* *}$ & 0 & SGP & $0.56^{*}$ & $3.7 *$ & 0.03 & 0.01 \\
\hline GIN & $1.08 *$ & $0.32 *$ & -0.04 & $0.1 * *$ & SLV & $4.25 *$ & $3.41 * * *$ & $0.12 *$ & 0.02 \\
\hline GNB & $1.08 *$ & $0.34 *$ & -0.01 & -0.05 & SWE & $0.3^{*}$ & $4.53 *$ & $0.11 *$ & $0.15^{*}$ \\
\hline GRC & $1.04 *$ & $0.32 *$ & -0.11 & -0.8 & SYR & $1.07 *$ & $0.38 *$ & $0.14 * * *$ & $0.35^{*}$ \\
\hline GTM & $2.06 *$ & $4.02 *$ & -0.2 & -0.11 & TGO & $1.08 *$ & $0.37 *$ & 0 & $0.09 * * *$ \\
\hline GUY & $1.84 *$ & $4.06^{*}$ & $0.2 * *$ & $0.29 * *$ & THA & $1.73 *$ & $4.56^{*}$ & -0.07 & -0.11 \\
\hline HND & $4.35^{*}$ & 3.17 & 0.03 & 0.01 & TTO & $1.72 *$ & $4.78^{*}$ & -0.23 & -0.11 \\
\hline HTI & $4.22 *$ & $3.67 * *$ & 0.02 & 0.01 & TUN & $2.01 *$ & $4.28 *$ & $0.26^{*}$ & $0.14 * *$ \\
\hline HUN & $1.05^{*}$ & 0.26 & $0.18^{*}$ & -0.13 & TUR & $1.08 *$ & $0.32 *$ & 0.03 & 0.05 \\
\hline IDN & $2.17 *$ & $4.23 *$ & -0.28 & -0.15 & TZA & $1.97 *$ & $4.53^{*}$ & -0.25 & -0.22 \\
\hline IND & $1.88^{*}$ & $3.35^{*}$ & $0.25 * * *$ & -0.03 & UGA & $4.15^{*}$ & $3.7 * *$ & -0.06 & -0.05 \\
\hline IRL & $0.74 *$ & $4.62 *$ & 0.08 & $0.13 * * *$ & URY & $1.88^{*}$ & $4 *$ & $0.32 * *$ & -0.03 \\
\hline IRN & $1.06^{*}$ & $0.32 *$ & $0.41 *$ & 0.01 & USA & $1.12 *$ & $4.2 *$ & -0.12 & -0.14 \\
\hline ISL & $0.35^{*}$ & $3.89 *$ & $0.33 * *$ & -0.04 & VEN & $1.83^{*}$ & $4.24 *$ & 0 & 0.07 \\
\hline ISR & $1.01 *$ & $0.35 *$ & $0.32 *$ & 0.16 & VNM & $1.08 *$ & $-0.04 *$ & $1.33 *$ & -0.67 \\
\hline ITA & $0.75^{*}$ & $4.28 *$ & $0.4 * * *$ & -0.11 & ZAF & $4.1 *$ & $4.06^{*}$ & $0.04 * *$ & 0.01 \\
\hline JAM & $1.76^{*}$ & $4.51 *$ & $0.25^{*}$ & $0.15^{*}$ & ZAR & $1.08 *$ & $0.36^{*}$ & 0 & 0.05 \\
\hline JOR & $1.08 *$ & $0.35^{*}$ & $0.39 * *$ & 0.04 & ZMB & $2.05 *$ & $4.45^{*}$ & $0.21 *$ & 0.08 \\
\hline JPN & $1.01 *$ & $0.32 *$ & 0.02 & 0 & ZWE & $1.82 *$ & $3.82 *$ & -0.66 & -0.7 \\
\hline
\end{tabular}

Notes: *Significant at 1 percent, **Significant at 5 percent and *** Significant at 10 percent. 
Table 3: Derivatives from the Semiparametric Model

\begin{tabular}{|c|c|c|c|c|c|c|c|c|c|}
\hline CCODE & $\phi_{1}$ & $\phi_{2}$ & $\phi_{3}$ & $\phi_{4}$ & CCODE & $\phi_{1}$ & $\phi_{2}$ & $\phi_{3}$ & $\phi_{4}$ \\
\hline ALB & 0.4874 & $0.45^{*}$ & $0.28 *$ & -0.00023 & KOR & 0.3462 & 0.14 & $0.60 * *$ & -0.00006 \\
\hline ARE & 0.0382 & -0.08 & -0.07 & $0.00147 * * *$ & KWT & 0.2665 & -0.08 & $0.27 *$ & 0.00008 \\
\hline ARG & 1.3999 & $0.19 * *$ & $0.65^{*}$ & $0.05216^{*}$ & LBR & 0.3922 & -0.45 & -0.05 & 0.00092 \\
\hline AUS & 0.6566 & $0.21 *$ & $0.67 *$ & $0.00396^{*}$ & LKA & 1.6356 & 0.14 & $0.60 *$ & 0.00188 \\
\hline AUT & 0.3588 & $0.16 * * *$ & $0.58 * * *$ & 0.00035 & LUX & 0.1896 & 0.12 & $0.68^{*}$ & -0.00864 \\
\hline BEL & 0.3563 & $0.17 * *$ & $0.77 *$ & -0.00033 & MAR & 1.5302 & $0.18 * *$ & $0.32 *$ & 0.00115 \\
\hline BGD & 1.6748 & 0.1 & $0.43^{*}$ & $0.06714 *$ & MDG & 1.6522 & $0.16 * * *$ & $0.32 *$ & $0.01746^{*}$ \\
\hline BGR & 0.4798 & -0.11 & $0.28 *$ & -0.00295 & MEX & 0.9184 & $0.18 * *$ & $0.33 *$ & -0.00749 \\
\hline BOL & 1.6169 & $0.17 * * *$ & $0.48 *$ & $0.06387^{*}$ & MLI & 1.6676 & 0.08 & $0.29 *$ & $0.05277 *$ \\
\hline BRA & 1.2871 & $0.18 * *$ & $0.66^{*}$ & -0.00032 & MOZ & 1.7502 & -0.05 & $0.62 *$ & $0.00494 *$ \\
\hline BWA & 0.4044 & $0.22 *$ & $0.26^{*}$ & $0.00372 *$ & MWI & 1.663 & -0.01 & $0.64 *$ & -0.00026 \\
\hline CAN & 0.6272 & $0.19 * *$ & $0.67 *$ & 0.00026 & MYS & 1.4944 & 0.13 & $0.68 *$ & 0.00033 \\
\hline CHE & 0.1118 & -0.09 & $0.68 *$ & $0.00309 *$ & NER & 0.3569 & $0.21 *$ & $0.11^{* *}$ & 0.00007 \\
\hline CHL & 0.3255 & $0.21 *$ & $0.37 *$ & 0.00049 & NGA & 1.794 & 0.1 & $0.33 *$ & $0.00738 *$ \\
\hline CHN & 0.2672 & $0.03 *$ & $0.68 *$ & 0.00054 & NIC & 1.6605 & $0.15 * * *$ & $0.58 *$ & -0.00032 \\
\hline CIV & 1.6641 & $0.16 * * *$ & $0.33 *$ & $0.00238 * * *$ & NLD & 0.4163 & 0.24 & $0.68 *$ & -0.0058 \\
\hline CMR & 1.7837 & $0.15 * * *$ & $0.33^{*}$ & -0.00033 & NOR & 0.4359 & $0.22 *$ & -0.05 & -0.00025 \\
\hline COL & 1.556 & $0.15 * * *$ & $0.58 *$ & -0.00027 & NZL & 0.6378 & $0.19 * *$ & $0.67 *$ & $0.00347 * *$ \\
\hline CRI & 1.0229 & $0.22 *$ & $0.68 *$ & -0.0003 & OMN & 0.4748 & 0.04 & $0.35^{*}$ & $0.00386^{*}$ \\
\hline DNK & 0.2979 & 0.28 & $0.68 *$ & -0.00386 & PAK & 1.6633 & 0.12 & $0.32 *$ & 0.00124 \\
\hline DOM & 1.3097 & $0.20 *$ & $0.65 *$ & $0.06988 *$ & PAN & 1.6467 & $0.19 * *$ & $0.54^{*}$ & 0.00066 \\
\hline DZA & 1.2481 & -0.01 & $0.60 *$ & $0.00391 *$ & PER & 1.1309 & 0.12 & $0.32 *$ & $0.00503 *$ \\
\hline ECU & 1.4293 & $0.18 * *$ & $0.67 *$ & $0.01203^{*}$ & PHL & 1.0441 & $0.15 * * *$ & $0.33^{*}$ & 0.00029 \\
\hline EGY & 1.6805 & 0.09 & $0.59 *$ & 0.00015 & PNG & 0.3921 & $0.14 *$ & $-0.15^{*}$ & -0.00025 \\
\hline ESP & 0.4639 & $0.65^{*}$ & $0.68 *$ & -0.00862 & POL & 0.4679 & -0.1 & $0.23 *$ & -0.00023 \\
\hline ETH & 1.7157 & -0.04 & $0.59 *$ & $0.00745^{*}$ & PRT & 0.2659 & 0.06 & $0.41 *$ & -0.00028 \\
\hline FIN & 0.4578 & $0.21 *$ & 0.2 & $0.00577 *$ & PRY & 1.6636 & $0.15^{* * *}$ & $0.53 *$ & $0.02543^{*}$ \\
\hline FRA & 0.9036 & $0.21 *$ & $0.64 *$ & 0.00045 & ROM & 0.4391 & -0.05 & $0.15^{*}$ & $0.00552 *$ \\
\hline GAB & 0.4313 & -0.09 & $0.09 *$ & -0.00007 & SAU & 0.3428 & 0.04 & $-0.14 * *$ & -0.00019 \\
\hline GBR & 0.9044 & $0.20 *$ & $0.67 *$ & 0.00045 & SDN & 0.3533 & 0.1 & $0.18 *$ & 0.00115 \\
\hline GHA & 1.6629 & 0.13 & $0.33 *$ & $0.01004 *$ & SEN & 1.6603 & 0.14 & $0.32 *$ & $0.00839 *$ \\
\hline GIN & 0.3543 & $0.04 *$ & $0.45^{*}$ & $0.00644 *$ & SGP & 0.4289 & $0.22 *$ & $0.55^{*}$ & -0.00762 \\
\hline GNB & 0.3368 & 0.1 & $-0.12 * *$ & 0.00033 & SLV & 1.2358 & 0.1 & $0.33 *$ & 0.00016 \\
\hline GRC & 0.4466 & $0.58 *$ & $0.68 *$ & $0.00402 *$ & SWE & 0.463 & $0.22 *$ & 0.21 & -0.00005 \\
\hline GTM & 1.6635 & $0.14 * * *$ & $0.48 *$ & $0.05646^{*}$ & SYR & 0.3909 & -0.12 & $0.53 *$ & 0.00049 \\
\hline GUY & 1.6428 & -0.08 & 0.04 & -0.00026 & TGO & 0.3513 & 0.02 & $0.09 * *$ & 0.00028 \\
\hline HND & 1.2397 & 0.11 & $0.32 *$ & $0.00528 *$ & THA & 0.8912 & -0.01 & $0.30 *$ & -0.00028 \\
\hline HTI & 1.6726 & 0.04 & $0.30^{*}$ & -0.00033 & TTO & 0.9976 & $0.21 *$ & $0.47 *$ & 0.00081 \\
\hline HUN & 0.4295 & -0.09 & $0.18 *$ & -0.00013 & TUN & 1.6641 & 0.14 & $0.62 *$ & 0.00028 \\
\hline IDN & 1.7109 & 0.09 & $0.51 *$ & $0.03679 *$ & TUR & 0.4635 & $0.17 * *$ & $0.66^{*}$ & $0.00298 *$ \\
\hline IND & 1.4126 & $0.15 * * *$ & $0.66^{*}$ & 0.00006 & TZA & 1.6637 & -0.02 & $0.67 *$ & 0.00045 \\
\hline IRL & 0.3592 & 0.13 & $0.74 *$ & -0.00863 & UGA & 1.7402 & 0.11 & $0.29 *$ & $0.00357 * *$ \\
\hline IRN & 0.4555 & -0.08 & $0.89 *$ & 0.00029 & URY & 1.3731 & $0.20 *$ & $0.61 *$ & -0.0001 \\
\hline ISL & 0.4412 & -0.11 & $0.25^{*}$ & -0.0001 & USA & 0.3539 & $0.20 *$ & $0.67 *$ & -0.00632 \\
\hline ISR & 0.4736 & $0.58 *$ & $0.68 *$ & -0.00029 & VEN & 1.2954 & $0.19 * *$ & $0.66^{*}$ & $0.04696^{*}$ \\
\hline ITA & 0.3569 & $0.15 * * *$ & $0.76^{*}$ & 0.00009 & VNM & 0.3425 & 0.07 & $0.28 *$ & 0.00067 \\
\hline JAM & 1.3915 & $0.21 *$ & $0.60 *$ & $0.02726 *$ & ZAF & 1.4008 & $0.20 *$ & $0.35^{*}$ & 0.00124 \\
\hline JOR & 0.4598 & -0.03 & $0.67 *$ & $0.00577 *$ & ZAR & 0.3554 & -0.08 & -0.72 & $0.00434 *$ \\
\hline
\end{tabular}




\begin{tabular}{|llllllllll||}
\hline & & & & & & & & & \\
JPN & 0.4103 & -0.29 & $0.68^{*}$ & 0.0003 & ZMB & 1.654 & -0.01 & $0.68^{*}$ & -0.00032 \\
KEN & 1.5811 & $0.04 *$ & $0.68^{*}$ & $0.00598^{*}$ & ZWE & 1.4227 & -0.03 & $0.66^{*}$ & -0.00012 \\
\hline
\end{tabular}

Notes: *Significant at 1 percent, **Significant at 5 percent and *** Significant at 10 percent.

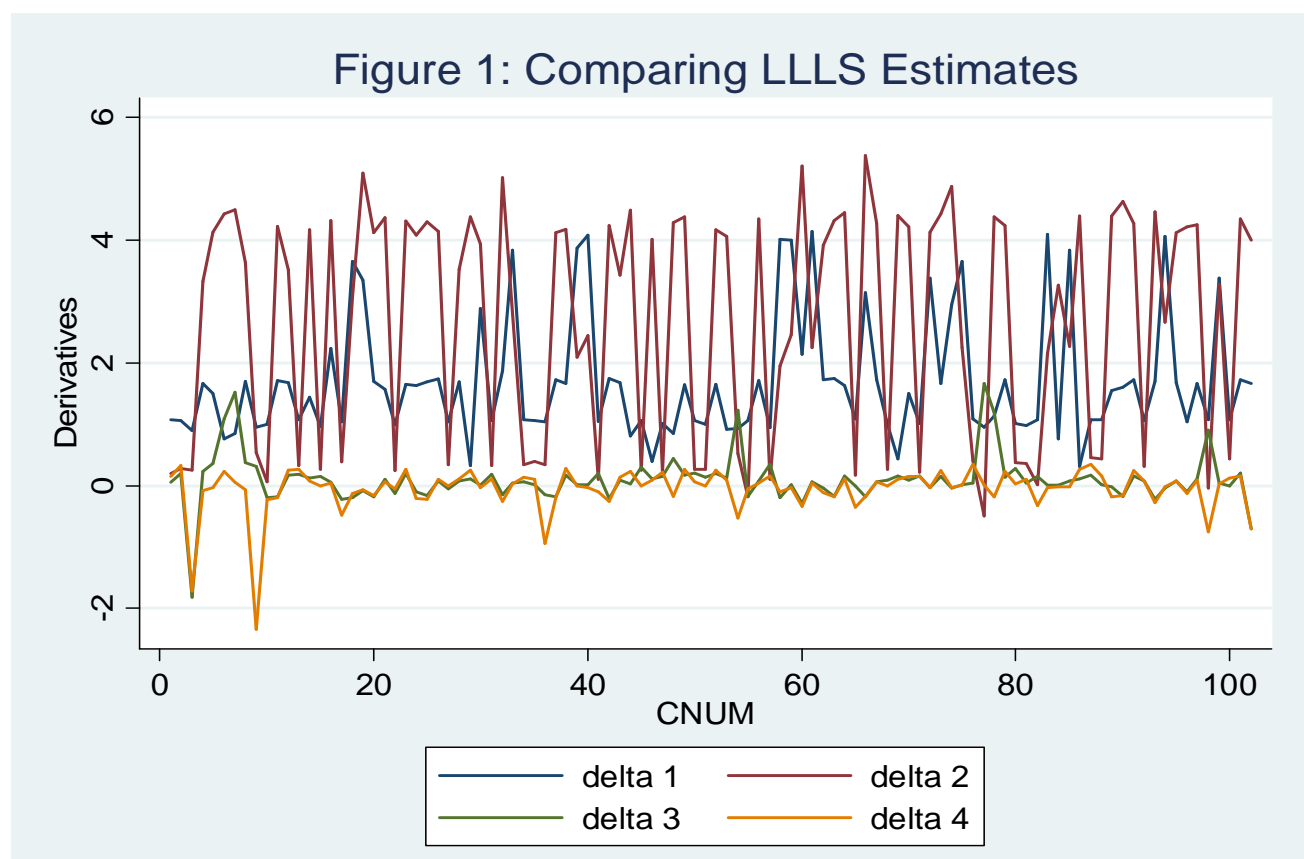

$*$ Note: delta $1=\delta_{1}$, delta $2=\delta_{2}$, delta $3=\delta_{3}$ and delta $4=\delta_{4}$. See A3 for CNUM.

Figure 2: Comparing LLGLS Estimates

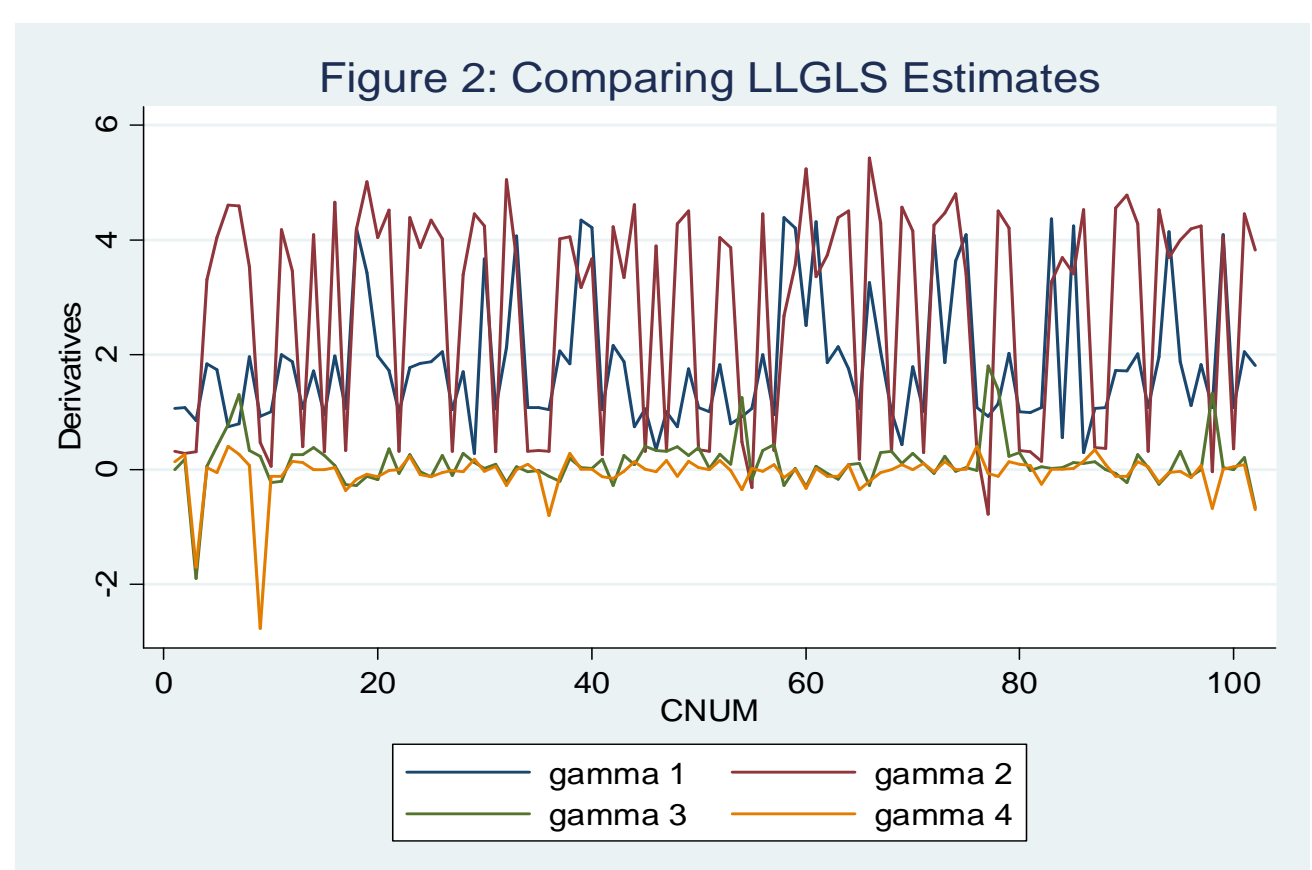

*Note: gamma $1=\gamma_{1}$, gamma $2=\gamma_{2}$, gamma $3=\gamma_{3}$ and gamma $4=\gamma_{4}$. See A3 for CNUM. 
Figure 3: Comparing Semiparametric Estimates

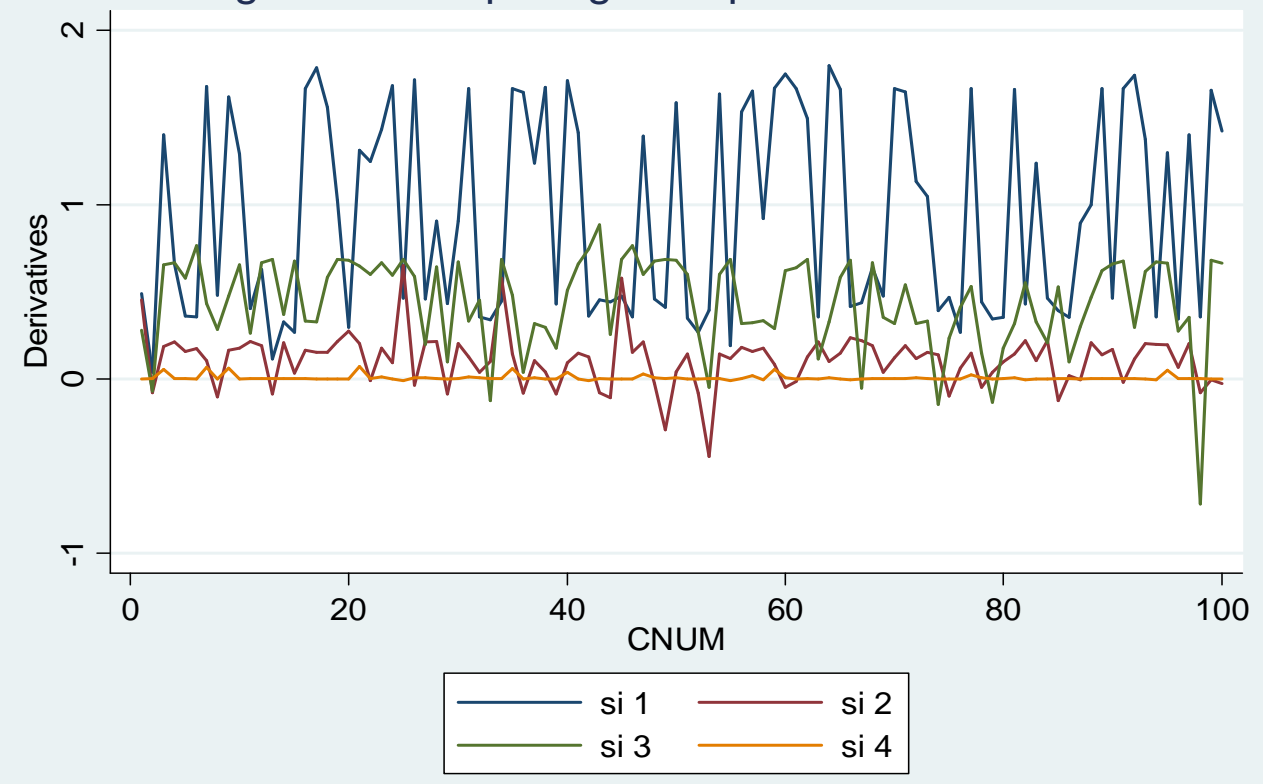

*Note: si $1=\phi_{1}$, si $2=\phi_{2}$, si $3=\phi_{3}$ and si $4=\phi_{4}$. See A3 for CNUM. 


\section{Annex Tables}

Table A1: List of countries in sample

\begin{tabular}{|c|c|c|c|}
\hline Country Code & OECD (22) & Country Code & Latin America (22) \\
\hline AUS & Australia & $\mathrm{BOL}$ & Bolivia \\
\hline JPN & Japan & $\mathrm{COL}$ & Colombia \\
\hline NZL & New Zealand & CRI & Costa Rica \\
\hline GRC & Greece & DOM & Dominican Republic \\
\hline PRT & Portugal & $\mathrm{ECU}$ & Ecuador \\
\hline CAN & Canada & GTM & Guatemala \\
\hline USA & United States & GUY & Guyana \\
\hline AUT & Austria & JAM & Jamaica \\
\hline BEL & Belgium & PER & Peru \\
\hline $\mathrm{CHE}$ & Switzerland & PRY & Paraguay \\
\hline DNK & Denmark & SLV & El Salvador \\
\hline ESP & Spain & HND & Honduras \\
\hline FIN & Finland & HTI & Haiti \\
\hline FRA & France & NIC & Nicaragua \\
\hline GBR & United Kingdom & ARG & Argentina \\
\hline IRL & Ireland & BRA & Brazil \\
\hline ISL & Iceland & CHL & Chile \\
\hline ITA & Italy & MEX & Mexico \\
\hline LUX & Luxembourg & PAN & Panama \\
\hline NLD & Netherlands & TTO & Trinidad and Tobago \\
\hline NOR & Norway & URY & Uruguay \\
\hline SWE & Sweden & VEN & Venezuela \\
\hline Country Code & Sub-Sahara Africa (26) & Country Code & Asia and Pacific (13) \\
\hline $\mathrm{AGO}$ & Angola & $\mathrm{BGD}$ & Bangladesh \\
\hline BWA & Botswana & $\mathrm{CHN}$ & China \\
\hline $\mathrm{CIV}$ & Cote d'Ivoire & IDN & Indonesia \\
\hline CMR & Cameroon & IND & India \\
\hline ETH & Ethiopia & KOR & Korea, Rep. \\
\hline GAB & Gabon & LKA & Sri Lanka \\
\hline GHA & Ghana & MYS & Malaysia \\
\hline GIN & Guinea & PAK & Pakistan \\
\hline GNB & Guinea-Bissau & SGP & Philippines \\
\hline KEN & Kenya & SGP & Singapore \\
\hline LBR & Liberia & THA & Thailand \\
\hline MDG & Madagascar & VNM & Vietnam \\
\hline MLI & Mali & PNG & Papua New Guinea \\
\hline $\mathrm{MOZ}$ & Mozambique & & \\
\hline MWI & Malawi & Country Code & Middle East and North Africa (13) \\
\hline NER & Niger & ARE & United Arab Emirates \\
\hline NGA & Nigeria & ISR & Israel \\
\hline SDN & Sudan & KWT & Kuwait \\
\hline SEN & Senegal & IRN & Iran, Islamic Rep. \\
\hline TGO & Togo & JOR & Jordan \\
\hline TZA & Tanzania & SYR & Syrian Arab Republic \\
\hline UGA & Uganda & BHR & Bahrain \\
\hline ZAF & South Africa & OMN & Oman \\
\hline ZAR & Congo, Dem. Rep. & SAU & Saudi Arabia \\
\hline ZMB & Zambia & DZA & Algeria \\
\hline \multirow[t]{2}{*}{ ZWE } & Zimbabwe & EGY & Egypt, Arab Rep. \\
\hline & & MAR & Morocco \\
\hline Country Code & EU and Other Europe (6) & TUN & Tunisia \\
\hline ALB & Albania & & \\
\hline BGR & Bulgaria & & \\
\hline ROM & Romania & & \\
\hline HUN & Hungary & & \\
\hline POL & Poland & & \\
\hline TUR & Turkey & & \\
\hline
\end{tabular}

Source: United Nations and World Bank 
Table A2: Development Quality Index (DQI) and Institutional Quality Index (IQI): Definition and Sources of Indicators

\begin{tabular}{|c|c|}
\hline Economic DQI & Economic IQI \\
\hline GDP per capita (PPP, \$ international 2000) & Legal and property rights ${ }^{3}$ \\
\hline Telephone mainlines (per 1,000 people) & Law and Order ${ }^{1 \mathrm{a}}$ \\
\hline Television sets (per 1,000 people) & Bureaucratic Quality $^{1 \mathrm{a}}$ \\
\hline Radios (per 1,000 people) & Corruption $^{1 \mathrm{a}}$ \\
\hline Electric power consumption (kwh per capita) & Democratic Accountability $^{1 \mathrm{a}}$ \\
\hline \multirow[t]{3}{*}{ Energy use (kg of oil equivalent per capita) } & Government Stability $^{1 \mathrm{a}}$ \\
\hline & Independent Judiciary $^{2}$ \\
\hline & Regulation $^{3}$ \\
\hline Health DQI & Social IQI \\
\hline Life expectancy at birth, total (years) & Press Freedom $^{3}$ \\
\hline Mortality rate, infant (per 1,000 live births) & Civil Liberties $^{3}$ \\
\hline Physicians (per 1,000 people) & Physical Integrity Index ${ }^{4}$ \\
\hline Immunization, DPT (\% of children ages $12-23$ months) & Empowerment Right Index ${ }^{4}$ \\
\hline \multirow[t]{4}{*}{ CO2 emissions (metric tons per capita) } & Freedom of Association $^{4}$ \\
\hline & Women's Political Rights $^{4}$ \\
\hline & Women's Economic Right $^{4}$ \\
\hline & Women's Social Right $^{4}$ \\
\hline "Knowledge DQI & "Political IQI \\
\hline $\begin{array}{l}\text { Literacy rate, adult total (\% of people ages } 15 \text { and } \\
\text { above) }\end{array}$ & Executive Constraint $^{6}$ \\
\hline School enrolment, primary (\% gross) & Political Rights $^{3}$ \\
\hline School enrolment, secondary (\% gross) & Index of Democracy $^{5}$ \\
\hline \multirow[t]{6}{*}{ Total number of years in schools ${ }^{1}$} & Polity Score $^{6}$ \\
\hline & Lower Legislative $^{2}$ \\
\hline & Upper Legislative $^{2}$ \\
\hline & Independent Sub-federal Units $^{2}$ \\
\hline & \\
\hline & \\
\hline
\end{tabular}

Note. For DQI, data obtained from the World Development indicators CD-ROM 2006, World Bank;

and ${ }^{1}$ Barro and Lee 2000 dataset, ${ }^{1 a}$ PRS Group (2005) ICRG database; ${ }^{2}$ POLCON Henisz Dataset; ${ }^{3}$ Economic Freedom Index dataset, Freedom House; ${ }^{4}$ CIRI Human Rights Data Project; ${ }^{5}$ PRIO Dataset; ${ }^{6}$ Polity IV Project 
Table A3: Countries and CNUM.

\begin{tabular}{|llllll|}
\hline CCODE & CNUM & CCODE & CNUM & CCODE & CNUM \\
\hline \hline AGO & 1 & GNB & 35 & NOR & 69 \\
ALB & 2 & GRC & 36 & NZL & 70 \\
ARE & 3 & GTM & 37 & OMN & 71 \\
ARG & 4 & GUY & 38 & PAK & 72 \\
AUS & 5 & HND & 39 & PAN & 73 \\
AUT & 6 & HTI & 40 & PER & 74 \\
BEL & 7 & HUN & 41 & PHL & 75 \\
BGD & 8 & IDN & 42 & PNG & 76 \\
BGR & 9 & IND & 43 & POL & 77 \\
BHR & 10 & IRL & 44 & PRT & 78 \\
BOL & 11 & IRN & 45 & PRY & 79 \\
BRA & 12 & ISL & 46 & ROM & 80 \\
BWA & 13 & ISR & 47 & SAU & 81 \\
CAN & 14 & ITA & 48 & SDN & 82 \\
CHE & 15 & JAM & 49 & SEN & 83 \\
CHL & 16 & JOR & 50 & SGP & 84 \\
CHN & 17 & JPN & 51 & SLV & 85 \\
CIV & 18 & KEN & 52 & SWE & 86 \\
CMR & 19 & KOR & 53 & SYR & 87 \\
COL & 20 & KWT & 54 & TGO & 88 \\
CRI & 21 & LBR & 55 & THA & 89 \\
DNK & 22 & LKA & 56 & TTO & 90 \\
DOM & 23 & LUX & 57 & TUN & 91 \\
DZA & 24 & MAR & 58 & TUR & 92 \\
ECU & 25 & MDG & 59 & TZA & 93 \\
EGY & 26 & MEX & 60 & UGA & 94 \\
ESP & 27 & MLI & 61 & URY & 95 \\
ETH & 28 & MOZ & 62 & USA & 96 \\
FIN & 29 & MWI & 63 & VEN & 97 \\
FRA & 30 & MYS & 64 & VNM & 98 \\
GAB & 31 & NER & 65 & ZAF & 99 \\
GBR & 32 & NGA & 66 & ZAR & 100 \\
GHA & 33 & NIC & 67 & ZMB & 101 \\
GIN & 34 & NLD & 68 & ZWE & 102 \\
\hline
\end{tabular}

